\title{
Mediating Effect of Team Identification in Team Climate for Innovation
}

\author{
Y. He
}

Management School, Donghua University, Shanghai, Chinas

\begin{abstract}
As the main body of innovation, team identification of research fellows to the team will encourage innovation activities in practical work. Therefore, the mediating effect of team identification is being analyzed between the effect of transformational leadership, team justice, and team norms to team climate for innovation (TCI). It turns out that the mediating effect of team justice, team norms to team climate innovation is more obvious. When team members feel team justice and team norms, there will be team identification to the team, which will improve employee satisfaction, and in turn promote their potential innovation, and innovation performance.
\end{abstract}

KEYWORD: Team Identification; Team Climate for Innovation; Mediating Effect; Influencing Factor

Team climate for innovation (TCI) is a perception of team members, this perception can not only be influenced by personal feature, but also team environment and Leadership traits, that is, TCI is not exit singly, therefore it is important to discuss the influencing factors of TCI. This discussion will help the manager to encourage the innovation potential of team members. To improve team performance by using TCI, it is necessary to clean up the characteristic of Chinese team and its influencing factors. Only in this way can explicit the formation mechanism of climate for innovation, and provide operational space for enterprise to structure its own team cliamte for innovation

\section{LITERATURE REVIEW AND HYPOTHESIS}

There are many influencing factors of TCI, the exiting literatures have provided many influencing factors from different perspectives. This paper summes these factors into 3 categories, i.e., transformational leadership, team justice, team norm. In teams, especially research team, transformational leadership can enhance the anticipation of team members to their own performance(Bass, 1995), therefore it is necessary to reshape the individual values and self-consciousness of team members to improve their demand level, and strengthen their innovation intention(Jung, 2000). Team justice can influence team creaticity by affecting innovation ability of team members. The development of TCI needs a corresponding climate to support innovatitive activities. However, the support of TCI to loyees' innovation is implicit, this increases the effect of team justice to the abilities of team members' innovation.

As intrinsic value and faith, team norms can restrain the employees' behavior into the norms offered by the team (Sherif, 1936, Thibaut and Kelley, 1959), meanwhile, this can guide individual behavior (Deshpande' and Webster Jr., 1989). This paper believes that the emploees will have loyalty to the team when they identify with the team. And when they increase their loytal, they will regard themselves as members of the team, and stay in step with the team in terms of value. This will lead them to indertake extra role work initiatively (Bergami and Bagozzi, 2000), i.e., they will prefer to finish creative work, and provide constructive comments and suggestions. Team Identification is a self coping attitude formed after the perceptions about team climate and the support from team leader. Studies have shown that team identification is very important to adjust internal behavior of employees and adapt to the external environment (Zhang, 2012). At present, much more attention has been paid to the mediating effect of identification to turnover intention, employee satisfaction and employee performance. However, the research on the effect of team identification to TCI is very few. This provides better research space for this paper to study the mediating effect of team identification between three influencing factors and TCI. 
Generally speaking, the identification of employees to team is mainly influenced by collective self, meanwhile, transformational leadership can influence collective self(Kark and Shamir, 2002), therefore influencs identification of the employee to the team. Through questionnaire survey anaysis of 360 technology companies, Mao \& Long (2006) found that transformational leadership can significantly influence the identification of the employee to team or organization; the researches of $\mathrm{He} \&$ Ling (2010) indicated that the strong identification of the employee to team leader would inevitably enhance their identification to the team; the researches of Liu et al.(2010) showed that transformational leadership can change the cognitive of the employee to the team or organization, which will earn the respect and credibility of employees, and enhance their identification. This paper believe that this identification will help to carry out innovative work. In a summary, transformational leadership value the employees' contribution to the team, which will enhance the employees' sense of participation and identity, and stimulate their creative potential.

In addition, team justice helps to form good team norms. When the emploee feel team justice and team norms, they will identify with the team, which will increase their team satisfaction, promote the development of creatice potential, improve innovation performance. Currently, the study on team justice and team norms is not so more. By taking 294 employees from 6 emmterprises, Qin et al.(2014) found that organizational justice can improve perceived organizational support, and foster their organizational identification; meanwhile this identification will encourage the employees to get through the difficulties, which is very important to innovative firms.

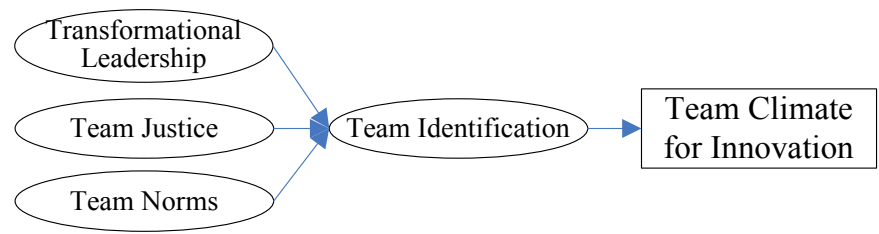

Figure 1 Mediating effect model of team identification

It can clearly be seen that transformational leadership, team justice and team norms can influence TCI by enhancing the employees' team identification. The employees possessing team identification will have positive work attitude and behavior, integrate personal goal into group goal, which will make them to upgrade the innovational ability on the interests of the team. Based on the above analysis, the mediating effect model of team identification of this paper is as Figure 1.

\section{DATA SOURCES AND EMPIRICAL ANALYSIS}

\subsection{Data Sources}

Firstly, this paper interviewed the research staffs of technology/product R\&D team by semi-structured questionnaire. According to the analysis of interviews, this paper compiled "Questionnaire on Structure Dimension and Influence Mechanism of Research and Development TCI". 525 questionnaires have been collected. Among these 525 respondents, female constituted $42.5 \%$, which means distributing sample is equilibrium. The age distribution is grouped mainly on 25-40. On the level of education, it is mainly on undergraduate and graduate.

\subsection{Research methods}

This paper adopted the test program of Wen et al. (2004), this method of testing can keep perfect control of probability of type 1 error. In order to better understand mediating effect, this paper described independent variable, dependent variable and mediating variables firstly. Assuming independent variable $x$ influences dependent $y$ through mediating variable $m$, the relationship of the three variables can be described into three formulas, and its roadmap is showed in Figure 2. Among which $c$ is the total effect of $x$ to $y$, and $a, b$ is the effect of of $x$ to $y$ through mediating variable $m$, which is call indirect effects. Under the fundamental assumption that $x$ is significantly correlated with $y$, the coefficient $c \neq 0$. Based on this, mediating variable $m$ is being calculated. This paper tested whether the difference of $c$ and $c$ is significant, that is the null hypothesis $H_{0}$ is $c-c^{\prime}=0$. If the null hypothesis is rejected, i.e., the mediating effect is significant (Clogg et al., 1992, Freedman \& Schatzkin, 1992). By using this program, this paper tests the mediating effect of team identification.

$$
\begin{array}{ll}
x c y & y=c x+e_{1} \\
x & e_{1}
\end{array}
$$

Figure 2 Sketch map of mediating variables

\subsection{Empirical analysis and results}

Firstly, normalization is being used to the variables of transformational leadership(L), team justice(J), team norms $(\mathrm{R})$, team identification(I) and TCI(T). Therefore, the mediating effect formula of "influencing factors-team identification-team climate for innovation" can be written as follows.

$$
T=c_{i} F+e_{i 1}
$$




$$
\begin{aligned}
& T=a_{i} F+e_{i 2} \\
& T=c_{i}^{\prime} F+b_{i} I+e_{i 3}
\end{aligned}
$$

Among which, $F$ denotes transformational leadership (L), team justice $(\mathrm{J})$, team norms $(\mathrm{R})$ seperately, and $a_{i}, c_{i}, c_{i}^{\prime}$ is the regression coefficients of influencing factor $i$, and $e_{i 1}, e_{i 2}, e_{i 3}$ are residual errors.

Table 1 Variance analysis table of TCI and three influencing factors

\begin{tabular}{|l|l|l|l|l|l|}
\hline Model & Sum of square & $d f$ & Mean square & $F$ & Sig. \\
\hline \multirow{4}{*}{ TL } & 35.96 & 1 & 35.96 & 259.90 & .000 \\
\cline { 2 - 7 } & 72.37 & 523 & .138 & & \\
\cline { 2 - 7 } & 108.33 & 524 & & & \\
\hline \multirow{4}{*}{ TN } & 28.233 & 1 & 28.23 & 184.35 & .000 \\
\cline { 2 - 7 } & 80.097 & 523 & .15 & & \\
\cline { 2 - 7 } & 108.330 & 524 & & 138.56 & .000 \\
\hline \multirow{3}{*}{ Tj } & 22.689 & 1 & 22.689 & & \\
\cline { 2 - 7 } & 85.64 & 523 & .16 & & \\
\cline { 2 - 7 } & 108.33 & 524 & & &
\end{tabular}

According to the procedure given by Wen, et al., this paper tests the significance of $c_{1}$. The results in Table 1 indicated that this regression model is significant ( $F=259.898, p<.001$ ), and the regression equation is statistically significant. Table 2 indicates that in $T=c_{1} L+e_{11}$, the standardized coefficients $c_{1}$ of transformational leadership to TCI is 0.576 , and its significance probability $p<.000$, which means $c_{1}$ is significant.

Table 2 Regression results of TCI and three influencing factors

\begin{tabular}{|l|l|l|l|l|l|}
\hline \multirow{2}{*}{ Model } & \multicolumn{2}{|l|}{$\begin{array}{l}\text { Unstandardized } \\
\text { Coefficients }\end{array}$} & $\begin{array}{l}\text { Standardized } \\
\text { Coefficients }\end{array}$ & \multirow{2}{*}{ Sig. } \\
\cline { 2 - 6 } & B & Std.Error & Beta & & \\
\hline (Constant) & $2.540 \mathrm{E}-5$ & .016 & & .002 & .999 \\
\hline TL & .398 & .025 & .58 & 16.12 & .000 \\
\hline (Constant) & $2.540 \mathrm{E}-5$ & .017 & & .001 & .999 \\
\hline TN & .361 & .027 & .51 & 13.58 & .000 \\
\hline (Constant) & $2.397 \mathrm{E}-5$ & .018 & & .001 & .999 \\
\hline TJ & .269 & .023 & .46 & 11.77 & .000 \\
\hline
\end{tabular}

Secondly, this paper tests the significance of coefficient $\alpha_{1}$. The regression result in Table 3 shows that this regression model is significant $(\mathrm{F}=159.775, \mathrm{p}<.001)$, which means the regression equation is statistically significant. Table 4 indicates that $\alpha_{1}$ in $I=a_{1} L+e_{12}$ is 0.484 , and its significance probability $<.000$, which means $\alpha_{1}$ is significant.
Table 3 Variance analysis table of team identification and three influencing factors

\begin{tabular}{|l|l|l|l|l|l|l|}
\hline \multicolumn{2}{|l|}{ Model } & $\begin{array}{l}\text { Sum of } \\
\text { square }\end{array}$ & $d f$ & $\begin{array}{l}\text { Mean } \\
\text { square }\end{array}$ & $F$ & Sig. \\
\hline \multirow{4}{*}{ TL } & Regression & 58.767 & 1 & 58.767 & 159.78 & .000 \\
\cline { 2 - 8 } & Residual & 192.365 & 523 & .368 & & \\
\cline { 2 - 8 } & Total & 251.131 & 524 & & & \\
\hline \multirow{4}{*}{ TN } & Regression & 12.434 & 1 & 12.434 & 27.24 & .000 \\
\cline { 2 - 8 } & Residual & 238.697 & 523 & .456 & & \\
\cline { 2 - 8 } & Total & 251.131 & 524 & & & \\
\hline \multirow{4}{*}{ TJ } & Regression & 15.601 & 1 & 15.601 & 34.64 & .000 \\
\cline { 2 - 8 } & Residual & 235.531 & 523 & .456 & & \\
\cline { 2 - 8 } & Total & 251.131 & 524 & & & \\
\hline
\end{tabular}

Table 4 Regression results of team identification and three influencing factors

\begin{tabular}{|l|l|l|l|l|l|}
\hline \multirow{2}{*}{ Model } & \multicolumn{2}{|l|}{$\begin{array}{l}\text { Unstandardized } \\
\text { Coefficients }\end{array}$} & $\begin{array}{l}\text { Standardized } \\
\text { Coefficients }\end{array}$ & $t$ & \multirow{2}{*}{ Sig. } \\
\cline { 2 - 6 } & B & Std.Error & Beta & & \\
\hline (Constant) & $3.810 \mathrm{E}-5$ & .026 & & .001 & .999 \\
\hline TL & .509 & .040 & .484 & 12.64 & .000 \\
\hline (Constant) & $3.810 \mathrm{E}-5$ & .029 & & .001 & .999 \\
\hline TN & .240 & .046 & .223 & 5.22 & .000 \\
\hline (Constant) & $3.692 \mathrm{E}-5$ & .029 & & .001 & .999 \\
\hline TJ & .223 & .038 & .249 & 5.89 & .000 \\
\hline
\end{tabular}

In the end, this paper test the significant of coefficient $c_{1}^{\prime}$ and $b_{1}$. According to the regression result shown in Table 5 , the regression model is sifnificant $(\mathrm{f}=132.79, \mathrm{P}<.001)$, which means the regression equation is statistically significant. Table 6 indicates that in equation $T=c_{1}^{\prime} L+b_{1} I+e_{13}$, coefficient $b_{1}$ is 0.536 , and its significance probability $\mathrm{p}<.000$, which means $b_{1}$ is significant. However, $\quad c_{1}^{\prime}=0.082$, and its significance probability $p=0.043<.05$, which means $c_{1}^{\prime}$ is significant. Through the analysis of mediating effect, this paper believes that team identification has an significant effect between transformational leadership and TCI.

Table 5 Variance analysis table of TCI, team identification and three influencing factors

\begin{tabular}{|l|l|l|l|l|l|l|}
\hline \multicolumn{2}{|l}{ Model } & $\begin{array}{l}\text { Sum of } \\
\text { square }\end{array}$ & $d f$ & $\begin{array}{l}\text { Mean } \\
\text { square }\end{array}$ & $F$ & Sig. \\
\hline \multirow{3}{*}{ TL } & Regression & 36.53 & 2 & 18.26 & 132.77 & .000 \\
\cline { 2 - 8 } & Residual & 71.80 & 522 & .14 & & \\
\cline { 2 - 8 } & Total & 108.33 & 524 & & & \\
\hline \multirow{4}{*}{ TN } & Regression & 34.17 & 2 & 17.09 & 120.27 & $.000^{\mathrm{a}}$ \\
\cline { 2 - 8 } & Residual & 74.17 & 522 & .14 & & \\
\cline { 2 - 8 } & Total & 108.33 & 524 & & & \\
\hline \multirow{3}{*}{ TJ } & Regression & 28.68 & 2 & 14.34 & 93.99 & .000 \\
\cline { 2 - 7 } & Residual & 79.65 & 522 & .15 & & \\
\cline { 2 - 7 } & Total & 108.33 & 524 & & & \\
\hline
\end{tabular}


Table 6 Regression results of TCI, team identification and three influencing factors

\begin{tabular}{|l|l|l|l|l|l|}
\hline \multirow{2}{*}{ Model } & \multicolumn{2}{|l|}{$\begin{array}{l}\text { Unstandardized } \\
\text { Coefficients }\end{array}$} & $\begin{array}{l}\text { Standardized } \\
\text { Coefficients }\end{array}$ & $t$ & \multirow{2}{*}{ Sig. } \\
\cline { 2 - 5 } & B & Std.Error & Beta & & \\
\hline (Constant) & $2.333 \mathrm{E}-5$ & .016 & & .001 & .999 \\
\hline TL & .371 & .028 & .536 & 13.17 & .000 \\
\hline TI & .054 & .027 & .082 & 2.02 & .043 \\
\hline (Constant) & $1.911 \mathrm{E}-5$ & .017 & & .001 & .999 \\
\hline TN & .251 & .024 & .407 & 10.63 & .000 \\
\hline TI & .165 & .025 & .251 & 6.566 & .000 \\
\hline (Constant) & $1.809 \mathrm{E}-5$ & .017 & & .001 & .999 \\
\hline TJ & .233 & .023 & .397 & 10.25 & .000 \\
\hline TI & .160 & .025 & .243 & 6.27 & .000 \\
\hline
\end{tabular}

By employing the same method, this paper analyzes the effect of team identification between team norms/team justice and TCI, and the results are showed in 错误! 未找到引用源。. According to this summary sheet, the null hypothesis $H_{0}$ : $c_{i}-c_{i}^{\prime}=0$ is being rejected, this means team identification has a significant mediating effect between three influencing factors and TCI. And the influence of transformational leadership to TCI seemed a little more than other two factors. However, there are bigger mediating effect between team norms/team justice and TCI. That means transformational leadership influences TCI directly, and team norms/team justice influencing TCI through team identification.

Table 7 Mediating effect summary of team identification

\begin{tabular}{|c|c|c|}
\hline & $\begin{array}{c}\text { Mediating effect of team } \\
\text { identification } c_{i}^{\prime}\end{array}$ & Total effect $c$ \\
\hline $\mathrm{TL} \rightarrow \mathrm{TCI}$ & 0.082 & 0.576 \\
\hline $\mathrm{TJ} \rightarrow \mathrm{TCI}$ & 0.251 & 0.511 \\
\hline $\mathrm{TNN} \rightarrow \mathrm{TCI}$ & 0.243 & 0.458 \\
\hline
\end{tabular}

\section{CONCLUSIONS AND POLICY RECOMMENDATIONS}

In summary, team identification can be seen as a self coping attitude formed after the perception to team climate. Standardized team management and fair team distribution can influence the identification of the employees to team. Only there is team identification, the team members can realize adequately effective interaction, and integrate peraonal goals with team goals. This will make the team member to enhance their own creative ability from the interest of team, and improve team performance. Through combining different members with different characteristics and different skills, R $\&$ D team can conquer difficult team work, so the management of team climate for innovation is not only to create a free and relaxed atmosphere, but to form team identification through standardized team management and fair team distribution. Only by real team identification, there will be lasting innovative cliame and health innovative performance.

\section{REFERENCES}

[1] Bass, B. M. 1995. Comment: Transformational Leadership. Looking at Other Possible Antecedents and Consequences. Journal of Management Inquiry, 4, 293-297.

[2] Bergami, M. \& Bagozzi, R. P. 2000. Self-categorization, affective commitment and group self - esteem as distinct aspects of social identity in the orgaiiization. British Journal of Social Psychology, 39, 555-511.

[3] Clogg, C. C., Petkova, E. \& Shihadeh, E. S. 1992. Statistical methods for analyzing collapsibility in regression models. Journal of Educational Statistics, 17, 51-74.

[4] Deshpande', R. \& Webster Jr., F. E. 1989. Organizational culture and marketing: Defining the research agenda. Journal of Marketing, 47, 101-110.

[5] Freedman, L. S. \& Schatzkin, A. 1992. Sample size for studying intermediate endpoints within intervention trials of observational studies. American Journal of Epidemiology, 136.

[6] He Li, Ling Wenlun. Effect of Leadership Style to Job Performance. Enterprise Economy, 2010, 11): 65-68.

[7] Jung, D. I. 2000. Transformational and Transactional Leadership and Their Effects on Creativity in Groups. Creativity Research Journal, 13, 185-195.

[8] Kark, R. \& Shamir, B. 2002. The dual effect of transformational and transactional leadership: priming relational and collective selves and further effects on followers. In: AVOLIO, B. \& YAMMARINO, F. (eds.) Transformational and charismatic leadership: The road ahead. Stamford, CT: JAI Press.

[9] Liu Zhao, Fan Jing, Zhang Huan. Research on the Effect of Leader Emotional Labor on Organizational IdentificationMediating Effect of Transformationl Leadership. The Theory and Practice of Finance and Economics, 2014, 05): 121-126.

[10]Mao Minxin Long Lirong. Study on the Relationship between Transf ormational Leadership and Employees ' Commitment to Organizational Change. Chinese Journal of Management, 2006, 6(5): 595-560.

[11]Qin Zhihua, Fu Sheng, Jiang Chengxiao. The Relationship between Organizational Justice and Organizational Identification: From the Perspective of Leader-member Exchange. Journal of Business Economics, 2010, 02): $37-$ 43.

[12] Sherif, M. 1936. The psychology of social norms, New York, Harper \& Brothers.

[13]Thibaut, J. W. \& Kelley, H. H. 1959. The social psychology of groups, New York, John Wiley \& Sons, Inc.

[14]Wen Zhonglin et al., Testing and Application of the Mediating Effects., Acta Psychologica Sinica 2004, 05): 614-620.

[15]Zhang Chao, A Study on the Relationship of Organizational Climate, Perceived Supervisory Support and Civil Servants' Innovation Intention: through the Intermediary of Organizational Identification; Southwestern University of Finance and Economics, 2012 